\title{
Suspected sepsis: summary of NICE guidance
}

The following changes have been made to the infographic in this Practice paper (BMJ 2016;354:i4030, doi:10.1136/bmj. i4030):

Added a high risk criterion "No response to social cues" for ages $0-4$

Changed value for moderate to high risk breathing criterion for age 3-4 from: 30-39 to 35-39

Split elevated temperature criterion in two: Under 3 months of age / $38+{ }^{\circ} \mathrm{C} /$ high risk 3-6 months of age / $39+{ }^{\circ} \mathrm{C} /$ moderate to high risk

Changed "temperature under $36^{\circ} \mathrm{C}$ " criterion for ages 5+from: High risk to Moderate to high risk

Changed heart rate criterion for age 12+from: 91-129 (moderate to high risk) and 130+(high risk) to 91-130 (moderate to high risk) and 131+(high risk)
Changed high risk systolic BP for age 12+from: under $90 \mathrm{mmh}$ to $90 \mathrm{mmHg}$ or less

Extended "Oxygen saturation $92 \%$ or less in air" to cover ages 5-11 as well as ages $0-4$.

Added "Apnoea" criterion for ages 0-4.

Removed "Moderate or severe chest indrawing for ages $0-11$.

Removed "Rigors" in 12+group.

Removed "Increased work of breathing" in 12+group.

Changed "Pale or flushed" criterion to: "Pallor of skin, lips or tongue." 